niet richten naar de door ons weergegeven opvattingen en niet aan eenige disciplinaire rechtspraak onderworpen zijn. Dit neemt echter niet weg, dat Observator niet schijnt te hebben opgemerkt, dat er toch ook accountants bij N.V.'s werkzaam zijn tegen wier arbejd de door hem genite bezwaren nict kummen worden ingebracht. Wij achten het dan ook waarschijnligk, dat de schrijver, indien hij cen juist inzicht had gohad in de beteekenis val dezen accountantsarbeid, zijn plan tot controle van Rijkswege niet zou hebben geopperd, maar veelecr zou hebben overwogen, hoe deze accountantscontrole bij de N.V. meer te verbreiden.

Beschouwen wij thans nader het eigenlijke plan van Observator.

Terstond treft de groote rol, die daarin aan den Staat wordt toebedeeld. Onwillekeurig homt men er toe het te vergelijken met de wettelijke regeling hies' te lande voor het levensverzekeringbedrịjf geschapen. Zelf trekt de schrịver deze parallel niet. Met zijn "Centraal College" en zijn ,schema's" correspondeeren cenigszins de Verzekeringskamer en de ,staten". Echtel springt cen principicel verschil in het oog, dat dadelịk voor het plan-Observator tot een gewichtige conclusic leidt. Richtsnoer voor de Verzekeringskamer zịn de belangen van polishouders, die zelf niet voor bun belangen kunnen op. komen en wicr: belangen onder de huidige omstandigheden gelden als een algemeen belang, dat staatsbemoeienis wettigt. Daarentegen bedoelt het "Centraal College" waarborgen te geven voor de bescherming van de belangen van aandeelhouders, waarvan het nog geenszins vaststaat, dat zij niet dooi de aandeelhouders zelf (rosp. op andere - eenvoudiger wịze) kunnen worden bchartigd. ${ }^{1}$ ) Frkent niet ook Observator (blz. 308), dat bij het beleggend publiek zelf evenzeer fouten moeten worden gezocht! De belangen van aandeelhouders zịn voorshands zuiver particuliere belangen, waarvoor zij zelf, nict de staat, hebben te waken. Ilet plan-Observator is een ongerijundheid, omdat het een in wezen socialistisch systeem wil aanwenden ten diensten niet van algemeene, maar van zuivel particuliere belangen.

Ook de doclmatigheid pleit tegen het plan-Observator. Zal in het steeds wissclende bedrijfsleven de onder zekere voorwaarden vrije arbeid van den public-accountant, wiens eer en goede naam op het spel staan en die zelf verantwoordelijkheid hraagt, niet grooter waarborg zijn voor aandeelhouders, dan die van den ambtenaar, bekonmerd om de stipte opvolging van schematische instrueties? Vervolgens stelle men zich eens voor, wat een ontzaglijke verantwoordelijkheid de Staat op zich zou nemen, indien hij zich verplichtte van alle naamlooze vennootschappen den waren stand en gang van zaken door middel van zijn ambtenaren aan commissarissen bloot te leggen. Tot welke financiëele staatsaansprakelijkheid zou dit kumnen leiden, wanneer deze ambtenaren fouten zouden maken, hetgeen niteraard niet zon uitblijven?

Overigens zal het na het voolafgegane geen verwondering wekken, dat het plan gedachten bevat, die in accountantskriugen, voorzoovee] ons bekend, wel als overwonnen kunnen wor' den beschouwd.

Dit geldt allereerst van het voorste] om voor iedere N.V. een Raad van Controle voor te schrijven, wat dus zou neerkomen op verplichte accountantscontroble bij de ongeveer 20.000 N.V.'s! Gceft de schrijver er zich wel rekenschap van, dat bij zeer vele, zoo niet de meeste, N.V.'s bescherming van aandeelhouder's tegenover bestuurder's een overlodigheid is on de ecnvoudige reden, dat aandeelhouders en bestuurders identiek zijn? Hetzolfde kan gezegd worden van het idee om de leden van de Raden ran Controle periodiek te doen aftreden: het stelsel der

1) Is immers in den laatsten tijd niet meer organisatie onder de beleggers war te nemen? Gewezen zij b.v. op het optreden der Vereeniging van Fondsenhouders. wisselende accountants vindt geen verdedigers, ondat het volledig leeren kennen van een zak zeer veel tijd eischt.

Wij laten het hierbij met onze eritiok op het plan zelf, ondat wij reeds het uitgangspunt van den schrijver verwierpen. Wij betwisten geenszins het bestaan van de door hem beschreven wantoestanden, maar wij wenschen ze op andere zijze te bestrijden. Het komt ons toch voor, dat als straks een strengere anispraticlijkheid van commissarissen in de wet zal worden vastgelegd, daardoor voor hen ontstaan zal een grootere behorfte aan objecticve voorlichting omtrent het bedrijf, die van zelf zal leiden tot een grootere verbreiding van de accountantsrontrole. Fr blijft dan nog de mogelijkheid, dat deze door onbevoegden zal worden uitgeoefend, hoewel de waarschịnlịikheid groot is, dat, waar de keuze van een accountant dan rechtstreeks en persoonlijk den commissarissen aangaat, de practijk wel de goede accountants van de pseudo-accountants zal weten te onderscheiden. In ieder geval lijkt een ingrijpen van den wetgaver op dit punt, mocht het noodig zijn, doeltreffender, convondiger en voor den Staat minder risquant, dan cen wettelijke regeling van het N.V.-wezen als door Observator voorgestcld.

Mr. E. A. HOFMAN

\section{EEIT EN ANDER OMTRENT AANTEEKENINGEN EN VASTLEGGINGEN}

Updat de accountant

reeds gedurende de uitvoering ecner controle: een inzicht kan verkrijgen in de doclmatigheid van inrichting der administratie en

na beëindiging der controle:

in staat is, met behulp van door eigen waarneming ver'kregen gegevens, de juistheid en volledigheid der jaalrekening c.a. tc bcoordeelen, resp. weten wat aan die juistheid en volledigheid ontbreekt.

moet door hem en zịne assistenten tịjdens de contrổe aantrekening worden gehouden van resp. worden vastgelegd:

$1^{\circ}$ de boekingen, welke volgens zijn inzicht technisch of om principiëele redenen niet juist zij̣n.

VOORBEFLD: Technische fout, indien eene ingekomen factuur in het Inkoopboek met een foutief bedrag is geboekt (omzetting van eijfers o.a.)

Principiëels fout, indien voor de verdeeling der indilecte kosten over de afdeclingen in een fabrieksbedrijf een onjuist omslag-percentage is toegepast, doordat bij het vaststellen der bases daarvoor, onvoldoende rekening is gehouden met het causaal verband tusschen bases on indircete kosten.

20. de bockingen, welke om de wijze van boeken of om het karakter der transactie, welke annleiding tot de boeking gaf, eene nadere toelichting van de zijde van den cliënt behoeven,

VOORBETILD: Wijze van bocken, indien bij de boeking der arbeidsloonen in het Kasboek, een deel daarvan nict onder Loonen, doch ten laste van eene andere rekening is gebockt, terwijl het de gewoonte is, de vordeeling der loonen via een loonsplitsing-boek te doen geschieden.

Karalter der transactie, indien in eene fabrick van emballage-artikelen in het Inkoopboek de boeking eener factuu over een geleverden wagon aardappelen wor'dt aangetroffen.

$3^{\circ}$. de hiaten en gebreken in de boekhouding, bezien van het standpunt van den controleerenden accountant, 
VOORBEELD : Hiaten = ontbrekende bescheiden als inkoopfacturen kwitanties en\%.

Gebreken $=$ onsystematisch of slordig opbergen van boekingsbescheiden.

$4^{\circ}$. de bedragen en gegevens - niet vallende onder de sub 1 tot 3 bedoclde - welke de controleur tijdens zijne contrôle. hetzij aan de boekhouding ontleent, hetzij zelfstandig verzamelt, ter uitvoering van de werkzaamheden, zooals die zijn voorgeschreven in het later te bespreken „Werkprogram'".

VOORBELLD : Gegevens arn cie boelitouding ontleend $=$ de maandtellingen der hulpboeken.

Zelfstandig veramelde gegevens = verrichte opnamen van kasgeld of vorraden.

A ANTEEKENINGEN. loor het maken van bedoelde aanteekeningen kan in het algemeen volstaan worden met een formulier, waarvan wij hieronder een model laten volgen:

(Naam Kantoor)

Dossier

Map

No.

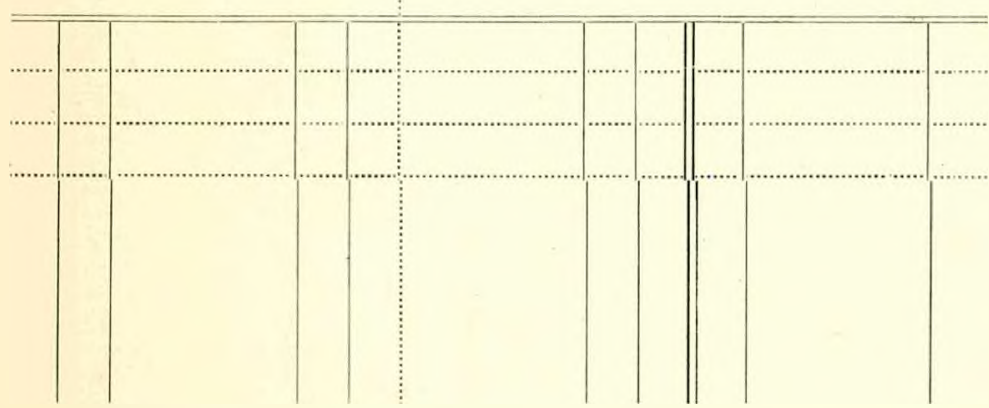

De indecling van dit formulier is er op berekend, dat voldaan kan worden aan de hoofdvoorwaarde, welke bij het inschrijven van alanteekeningen steeds in het oog gehouden moet worden 11.l. dat de aanteekening zoo duidelijk, maar tevens zoo beknopt mogelijk moet zijn. Het noteeren der aanteekeningen moet den assistenten niet meer tijd vragen dan strikt noodzakelijk is.

Het kont ons voor, dat het bestaan van deze voorwaarde in vele gevallen vergeten wordt en dat talrijke assistenten voor het maken van eene contrôle-aanteekening eenige regels schrift noodig hebben, terwij] in zulk een geval dikwijls met het vermelden van 2 of 3 cijfers rolstaan kan worden. De aanteekening kan even duidelijk blijven, doch vraagt dan maar een fractie van den tijj, noodig voor het geven van eene uitvoerige omschrij.jving.

Een voorbeeld zal dit verduidelijken.

Uit het gegeren model blijkt, dat dit formulier door eene dubbele verticale lijn in twee deelen is verdeeld, waarbij het linkerdeel ongeveer twee derden der breedte van het blad beslaat.

Dit linkerdeel is door eene verticale stippellijn weder in twee - ongeveer even breede - kolommen gescheiden, beide voolzien valn een geldkolom, teneinde voor geldbedragen, welke vooral bij de contrôle van hulpboeken veelvuldig in de aanteekeningen voorkomen, op het formulier eene bepaalde ruimte beschikbaar te laten.

Bedoeld linker-deel is te reserveeren voor de aanteekening; het rechterdeel om te vermolden, op welke wijze de gemaakte notitie is afgehandeld.

Indien nu b.v. bij de contrōle van het Inkoopboek met de facturen geconstatecrd wordt, dat factuur No. 893 van H. Jansen te Alkmaar, met een eindbedrag van $f 1462,68$, in het Inkoopbock geboekt is met een totaal van $f 1426,68$, kan de aanteekening daarvan en het later vermelden van den herstelpost op een contrôle-aanteeken-formulier, zooals op verschillende accountantskantoren in gebruik is en waarvan de indeeling cenigszins afwijkt van het hiervoor gegeven model, als volgt geschieden :

(Naam Kantoor)

Cliënt:

214

Doorl.

Map B No. $9 \quad \mathrm{c} / \mathrm{b}$

No.

\begin{tabular}{|c|c|c|c|}
\hline 28 & $\begin{array}{l}\text { Factuur No. } 893 \text { van H. } \\
\text { Jansen te Alkmaar be- } \\
\text { draagt in totaal ........ } \\
\text { doch is in het Inkoopboek } \\
\text { geboekt met .............. }\end{array}$ & $\begin{array}{l}f \quad 1462.68 \\
, \quad 1426.68\end{array}$ & $\begin{array}{l}\text { per Memoriaal } \\
\text { doen herstellen. } \\
\text { Zie Memoriaal } \\
\text { post No. } 46\end{array}$ \\
\hline
\end{tabular}

Deze aanteekening is duidelijk, maar niet bcknopt, aan welke beide eischen de volgende aanteekening van hetzelfde verschil wel voldoet:
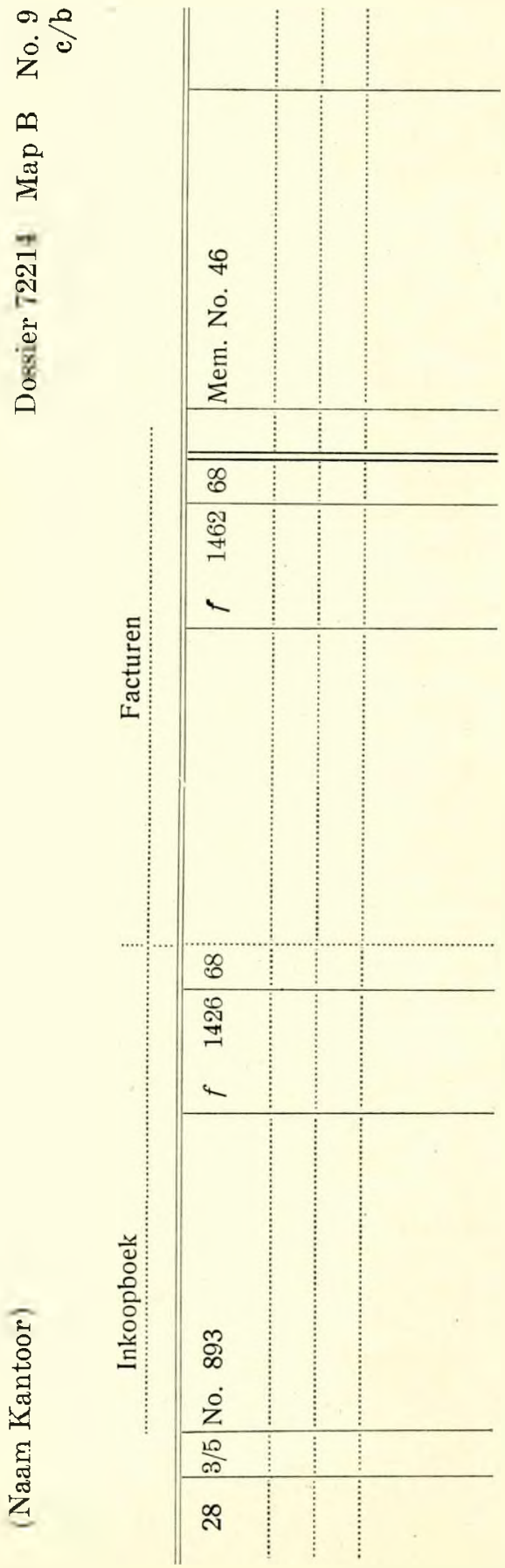
Wij moeten toegeven, dat nict voor alle te maken aanteekeningen met eene dergelijlise korte omschrijving volstaan kan worden, doch naar onze meening, zal de omschrijving van het overgroote deel der aanteekeningen in een zeer gecomprimeerden vorm gegeven kumen worden, ter bevestiging van welke meening het volgende voorbeeld nog moge dienen. Oogenschijnlijk is voor het duidelijk vermelden daarvan op de aanteckenlijst eene betrokkelijk lange omschrijving noodig, terwijl dit in werkelijkheid geenszins het geval behoeft te zijn.

VOORBELLD : Een eerste assistent constateert, bij de contrôle van het Inkoopbock met de inkoop-facturen, dat factuur' No. 893 van H. Jansen te Alkmaar ad $f 460.10$ niet is uitgeschreven ten name ran de Naamlooze Vennootschap - welker administratie voor de eerste maal door een accountant gecontroleerd wordt - doch ten name van den Directeur. Hij gaat daarop na, of roor de op deze factuur vermelde goederen ecne bestelbon is uitgeschreven on of zij in de Magazijn-administratie als ontvangen geboekt zijn, wat geen van beide het geval blijkt. Vervolgens bespreekt hij de kwestie met den procuratiehouder der N.V., die hem mededeelt:

$1^{\circ}$. dat deze goederen door den Directeur persoonlijk mondeling zijn besteld - de reden daartoe kan hier buiten beschouwing blijven - en de leverancicr daaruit begrepen had, dat de Iirecteur in privé voor het factuurbedrag belast moest worden;

$2^{\circ}$. dat de goederen niet in de magazijn-administratic zijn verantwoord, omdat zij door den leverancier direct aan den klant zịnn verzonden, wiens rekening er voor belast is.

Bij de contrôle der Verkoop-administratie blijkt dat inderdaad het geval te zijn.

(Wordt vervolgd)

G. HARTOG

\section{VERBETERING :}

In het roorgaand artikcl, voorkomende in het No. van December 192 $\%$, moet op bladz. 178, 1ste kolom, 16den regel v. o. voor: productie, worden gelezen : periodiciteit.

\section{EFFICIËNTIE Red. L. POLAK}

\section{Methoden tot verlaging van kosten in fabrieken}

Het Amerikaansche tijdschrift „Manufacturing Industries”, schreef in het Septembernummer een prijsvraag uit waarbij beschrijvingen gevraagd werden van willekeurige maatregelen of methoden, die in fabrieken tot verlaging van kosten gevoerd hebben. In het Novembernummer treffen we de eerste inzendingen op deze prijsvraag aan.

Een inzending op deze prijsvraag, die met een prijs van 50 dollar bekroond werd, is die van den Heer L. W. Downie, Factory Accountant, Kelsey Weel Cy. Ltd., die getracht heeft, door het vastleggen van een verhouding tusschen de directe en indirecte loonen te bereiken, dat het bedrag van de laatste bij elke bedrijfsdrukte binnen de daarvoor gestelde grenzen blijft.

Het uitgewerkte plan komt hierop neer, dat dagelijks, met nitschakeling van de vaste indirecte loonen, de verhouding wordt nagegaan tusschen direct en indirect loon en dat, inclien die verhouding niet die is, welke op grond van waarneming en tijdstudie als de juiste werd aangenomen, onmiddcllijk wordt ingegrepen, de oorzaak der afwijking wordt opgespoord en verwijderd.

Wij laten hier een vertaling van het door den Heer Downie ingezonden artikel volgen:

"In de afgeloopen jaren was het herhaaldelijk voorgekomen, dat tijdens een drukle maand extra arbeiders aangenomen werden voor algemeene sjouwdiensten, kolen kruien, sjouw- dieusten in de verschillende fabrieksafdeelingen en dergelijke en dat, indien de bedrijvigheid vel'minderde het ontslag van deze tijdelijke arbeidskiachten veel te lang werd uitgesteld. Daardoor ontstond maand voor maand een wisselend opslag percentage voor de indirecte loonen".

Na een opgave van het bedrag, dat met het plan jaarlịks bespaard werd, een bijzonderheid, die voor een Hollander vrijwel nooit is vast te stellen en die steevast in alle Amerikaansche tijdschriften op de dollar af wordt aangegeven, gaat het artikel verder:

Voor ieder ,direct labor operation", van elk product, dat in die geheele fabriek gemaakt wordt, werd zorgvuldig door tijdstudies de standaardtijd rastgesteld. Met standaardtijd wordt hier bedoeld de tijd die onder normale omstandigheden daarvoor noodig is". (Fen uiteenzetting wat normale omstandigheden zijn, wordt niet gegeven, L.P.)

I) werkelijk verbruikte tijd wordt de ,actual time" genoemd.

De berekende standaard tijd of "standard hour" zooals deze verder genoemd wordt, wordt als maatstaf aangewend bij den opzet van de begrooting van de uit te betalen arbeidsloonen. De betrokken fabriek fabriceert een dusdanig antal artikelen, dat het niet mogelijk is het indirect loon per stuk fabrikaat te begrooten. Daarom wordt uitgegaan van de verschillende producten en aan de hand daarvan teruggerekend naar het aantal standaard uren dat daarvoor had mogen worden gebruikt. Dit gegeven wordt dan gebruikt on er de werkelijk gebruikte uren aan te toetsen.

Ook werd een gedetailleerde analyse gemaakt van alle ,production activities" van het afgeloopen jaar. Tabellen werden opgesteld waarin de productie per standard-hour voor jedere maand werd berekend. Hieruit werd een gemiddelde maand productic vastgesteld.

Vervolgens werd al het indirecte arheidsloon gedurende hetzolfde jaar betaald, in tabcllen gebracht, gesplitst naar maanden en naar soort van werk. Uit beide tabellen werden de kosten aan indirect loon per standard-hour van ieder soort van werk per maand en het gemiddelde per jaar berekend. Uit vergelijking der zoo berekende maandejjfers bleken van maand tot maand belangrijke afwijkingen, die verklaard werden, door het feit dat het antal indirect werk verrichtende arbeiders niet onmiddellijk op en neer gaat met de hoogere of lagere productie.

Vervolgens werd voor iedere fabrieksafdoeling het beduag begroot, dat voor een normals maand-productie (bedocld wordt hier de berekende gemiddelıle maand-productie van het afgeloopen jaar') noodig is. Op deze begrooting was mede het aantal arbeider's en het aantal begroote uren aangegeven, zoodat deze begrooting, die in overleg net den bedrijfsleider was opgemaakt aangaf, hoeveel indirect werk verrichtende arbeiders in iedere afdeeling waren toegestaan, het aantal uren per dag of per maand dat zij mochten werken en de loonen die betaald mochten worden indien de maand-productie cen hepaalde hoogte bereikte.

Verder kreeg de bedrijfsleider de tabellen van de verrichtingen in het afgeloopen jaar en van deze statistieken af., tezamen met zijn kennis van de fabriek kon hij handig met de cijfel's der begrootingen omspringen.

Vervolgens werd figuur 1 opgesteld. ${ }^{1}$ ) De toegestane uitgaven van elke fabrieksafdeeling werden verdeeld in drio groepen n.l. : vaste indirecte loonen, controleerbare loonen, en totaal arbeidsloon. "Vaste indirecte loonen" werden vaak onderverdeeld in arbcider's op vaste salarissen en arbeiders op vaste uurloonen, maar warop toch geen contröle mogelijk is, zooals b.v. nachtwaker's, stokers ete. De cijfers van deze twee ondergroepen zijn weer tezamen gebracht in de kolommen 7 en 8 en de kosten berekend per standaard uur ingevuld in kolom 9 .

Dit geheele gedeelte van het arbeidsloon is practisch nict te

1) Zie volgende bladzijden. 